\title{
Gender as a Moderator and its Moderating Effect on Relationship between Face Book usage and the Academic Performance of Government University Undergraduates in Sri Lanka
}

By P.D.V. Charika Wickramaratne, Dr. Syed Helmy Seyd Abu Bakar \& Prof. Jeong Chung Phuoc University of Kelaniya Abstract- From this Article, it is considered that the moderating effect of gender, for Facebook usage, and the academic performance of government university undergraduates in Sri Lanka. From 984 government university undergraduates were the respondents of this study, and the respondents were from the University of Peradeniya, University of Kelaniya, University of Colombo, and University of Sri Jayewardenepura. Gender is a moderate variable for the study. And there are 534 male undergraduate respondents, and 450 female respondents responded to the questionnaire. Using a multi - group analysis method identified the moderating effect on both male and female groups. According to the analysis results, proved that gender moderates the relationship between social media usage (Facebook) and the academic performance of the government university undergraduates in Sri Lanka.

Keywords: university undergraduates, facebook usage, 1academic performance, gender.

GJMBR-A Classification: JEL Code: M19

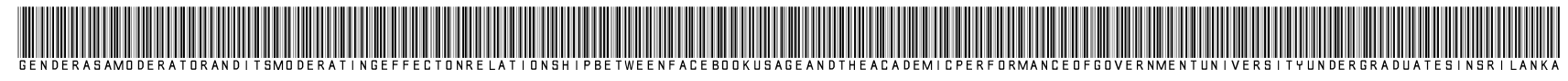

Strictly as per the compliance and regulations of:

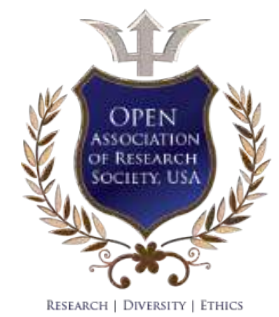

(c) 2019. P.D.V. Charika Wickramaratne, Dr. Syed Helmy Seyd Abu Bakar \& Prof. Jeong Chung Phuoc. This is a research/review paper, distributed under the terms of the Creative Commons Attribution-Noncommercial 3.0 Unported License http://creative commons.org/licenses/by-nc/3.0/), permitting all non-commercial use, distribution, and reproduction in any medium, provided the original work is properly cited. 


\title{
Gender as a Moderator and its Moderating Effect on Relationship between Face Book usage and the Academic Performance of Government University Undergraduates in Sri Lanka
}

\author{
P.D.V. Charika Wickramaratne ${ }^{\alpha}$, Dr. Syed Helmy Seyd Abu Bakar ${ }^{\sigma}$ \& Prof. Jeong Chung Phuoc ${ }^{\rho}$
}

Abstract From this Article, it is considered that the moderating effect of gender, for Facebook usage, and the academic performance of government university undergraduates in Sri Lanka. From 984 government university undergraduates were the respondents of this study, and the respondents were from the University of Peradeniya, University of Kelaniya, University of Colombo, and University of Sri Jayewardenepura. Gender is a moderate variable for the study. And there are 534 male undergraduate respondents, and 450 female respondents responded to the questionnaire. Using a multi - group analysis method identified the moderating effect on both male and female groups. According to the analysis results, proved that gender moderates the relationship between social media usage (Facebook) and the academic performance of the government university undergraduates in Sri Lanka.

Keywords: university undergraduates, facebook usage, 1academic performance, gender.

\section{INTRODUCTION}

$\mathrm{n}$ the modern world, community, including, university students facing more health risks because of using digital devices in the in- proper way. Therefore a high level of stress, lack of physical activity, poor diet habits, social isolation, and can be identified. (Shao et al. 2017) Thus their digital wellness (using digital devices effectively and efficiently) is the fact to achieve their targets in the academic field.

Therefore when giving attention to the academic performance of undergraduates and their wellness, student's digital wellness will be a major focus. Thus within this age of technology, establishing boundaries and healthy guidelines for relationships of humans with the technology will be a sustainable approval to maintain elements of their non - digital wellness.

Internet use by Age 2000-2010

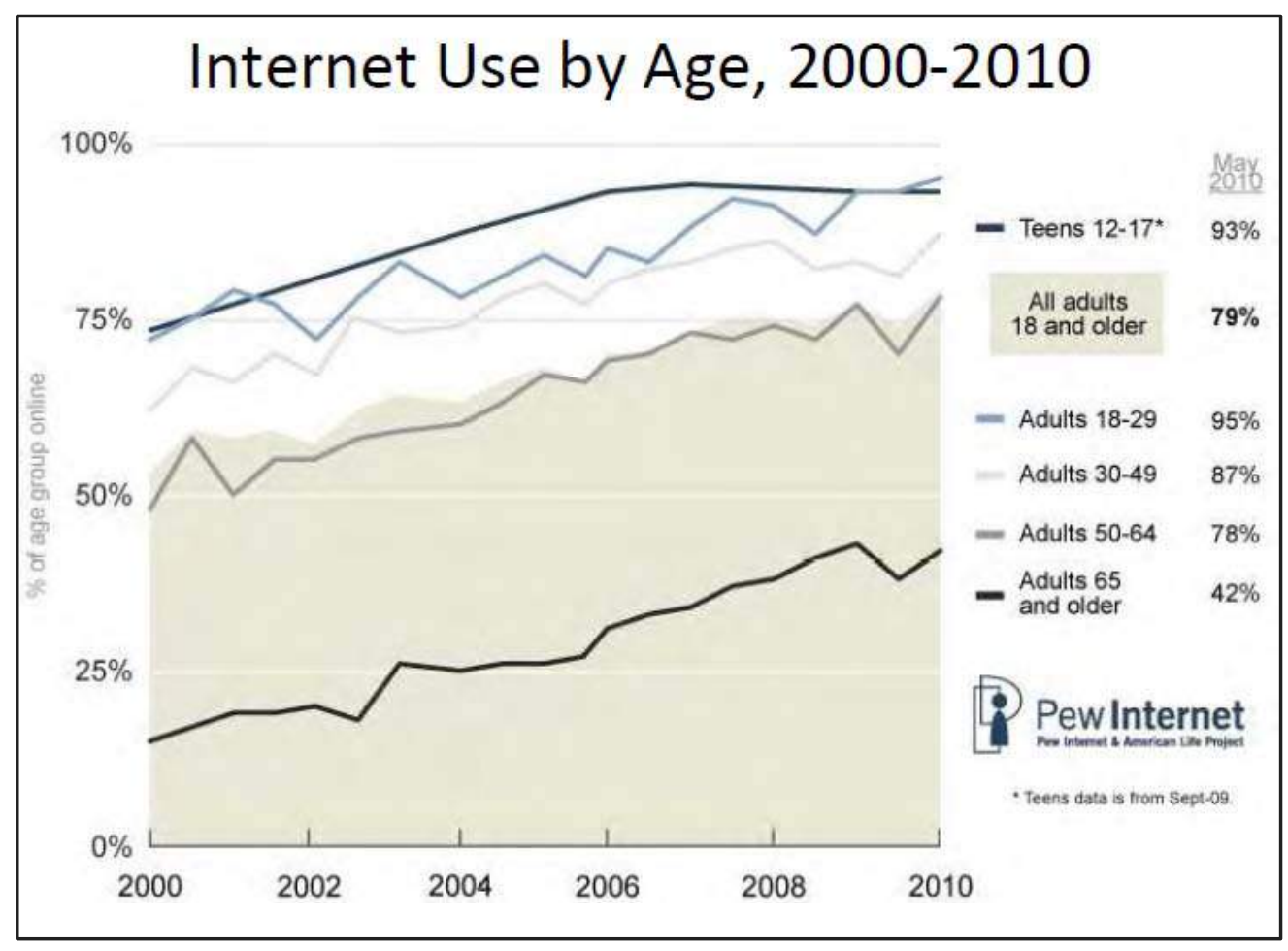

Figure 1

Author a: University of Kelaniya, Sri Lanka. e-mail: pdvcharika@gmail.com

Author $\sigma \rho$ : Management and Science University, Malaysia. 
Most of the University students are in the age between 19- 25 years. According to the above graph in the USA most of the internet users are age 18- 29 when comparing to previous years there is a gradual increase in using the internet, of above age between 18- 29. It is an example that university undergraduate is using digital devices because they are also in the same age category. According to Barnet $(2010$,$) most of the time,$ people age between18-29 are the high users of social media such as face book between years 2005-2010.

\section{Social Media Use by Age, 2005-2010}

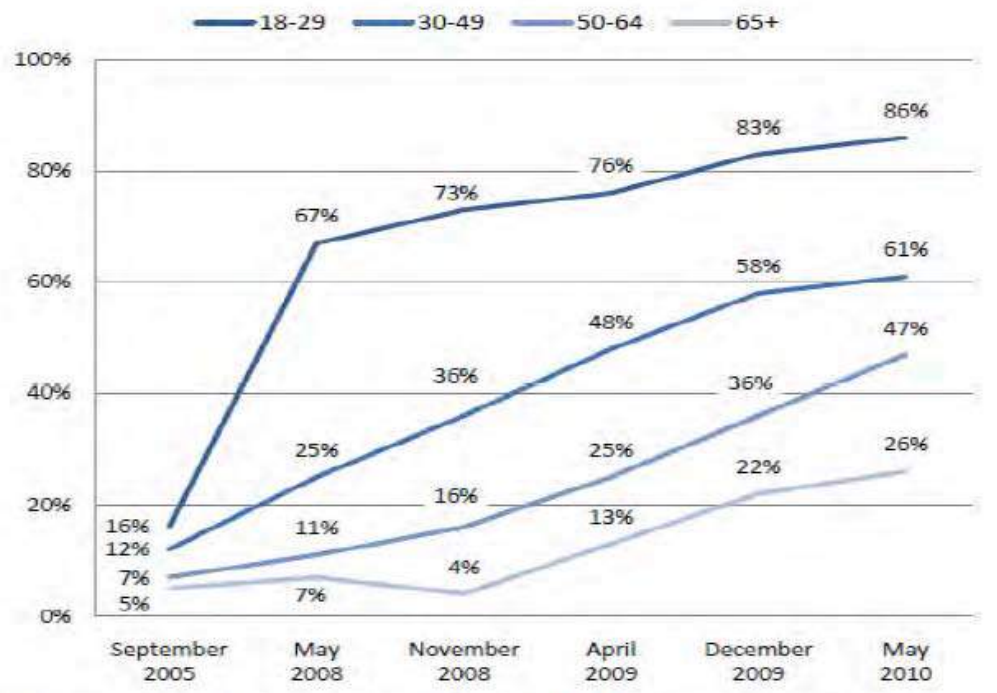

Source: Pew Research Center's Internet \& American Life Project Surveys, september 2005 May, 2010. All surveys are of adults 18 and older.

Figure 2

Generational Differences in online activities

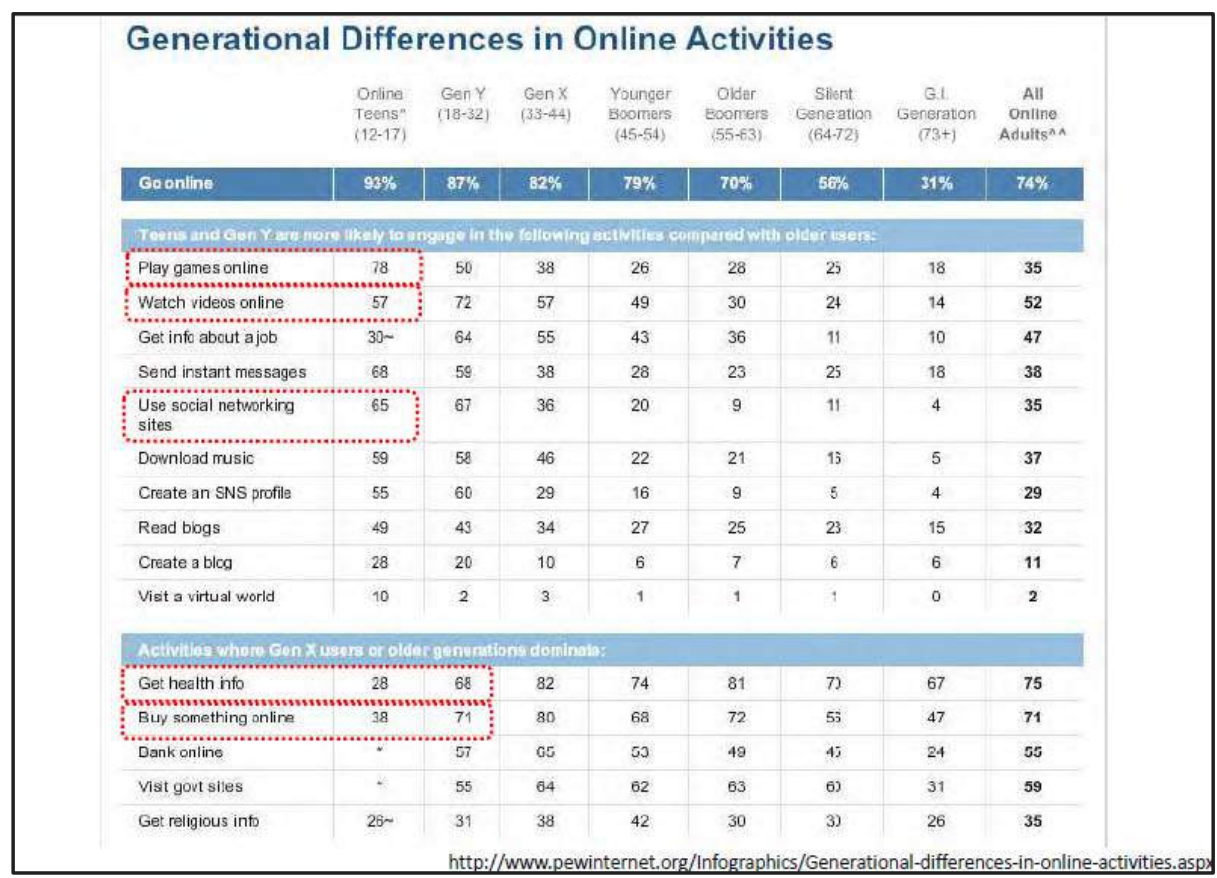

Figure 3

Figure 3 also confirms that most of the population from "X" and "Y" generation are using digital devices for entertainment rather than using them for educational purposes in the world. 
Frequency of using Social Media

\begin{tabular}{|c|c|c|c|}
\hline & & Number & Percentage \\
\hline \multirow{4}{*}{$\begin{array}{l}\text { Hours surf } \\
\text { internet in a day }\end{array}$} & $1 \mathrm{~h}$ or less & 3 & 6 \\
\hline & $2 \mathrm{~h}$ & 7 & 15 \\
\hline & $3 \mathrm{~h}$ & 18 & 38 \\
\hline & $4 \mathrm{~h}$ and above & 19 & 40 \\
\hline \multirow{4}{*}{$\begin{array}{l}\text { Hours surf social } \\
\text { media sites in a day }\end{array}$} & $1 \mathrm{~h}$ or less & 9 & 19 \\
\hline & $2 \mathrm{~h}$ & 11 & 23 \\
\hline & $3 \mathrm{~h}$ & 15 & 32 \\
\hline & $4 \mathrm{~h}$ and above & 12 & 26 \\
\hline \multirow{4}{*}{$\begin{array}{l}\text { Use of social } \\
\text { media sites for }\end{array}$} & Information sharing & 7 & 15 \\
\hline & Entertainment & 9 & 19 \\
\hline & Socializing & 11 & 23 \\
\hline & Above all & 20 & 43 \\
\hline
\end{tabular}

In the year 2017, Ali et al., from their study found that 261 of students were used face book for more than Hour per a day. According to the study the usage of face book one hour per a day is only $3 \%$, of the students. All the other users of Facebook is more than one hour per day. Most of them are using facebook for socializing and entertainment. Abusbiha's and Mustaffa 62 (2014), by citing Carr (2008), found that poor academic performance can be seen from students who are using the internet regularly. According to Hamilton

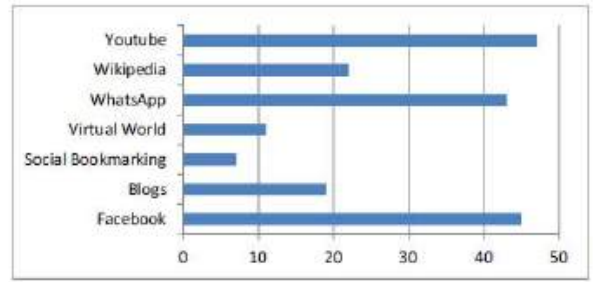

Figure 2 Frequencies of different social media applications.

lected show that 18.51 percent of students use these applications for socializing and learning, 37 percent for learning. 11.11 percent for entertainment and 33.33 percent for socializ-

(2009), most of the college students who are engaging in Facebook for more time, earn lower grade point average (GPA), than the students who are not logged in the face book for more time. Ali et al. (2017), by siting Kuppuswamy and Narayan (2010), found that those who are using social media for entertainment rather than using them for academic work, will gain lower grade point averages. More over According to khan (2012), more Facebook usage is negatively affected by the academic performance of college students.

Internet usage statistics in Sri Lanka

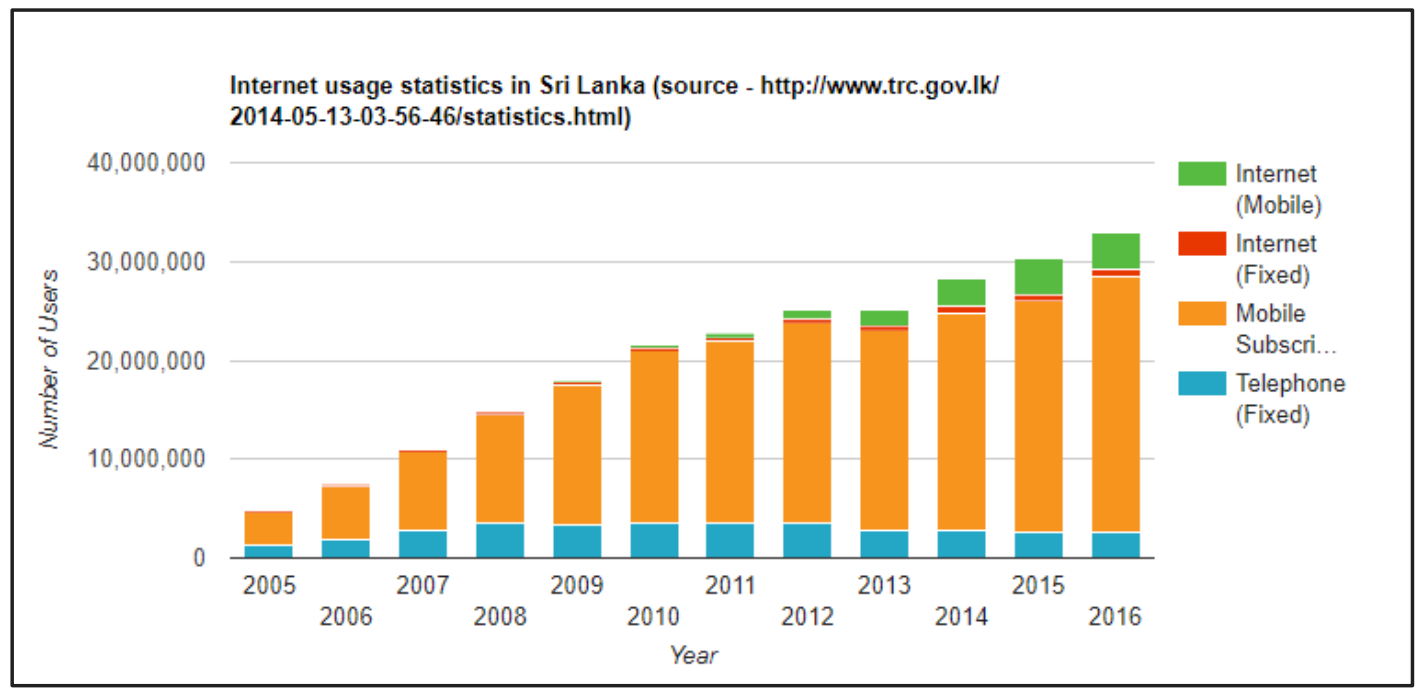

Weerasendara (2015) states that as a result of using in social media frequently, people were committed to suicide in Sri Lanka. There are 21 million people who live in Sri Lanka, and mobile phone usage is 22 million (Jinadasa, 2016). Also, the usage of mobile phones within the youth is increasing rapidly. According to Ananda et al. (2015),Sri Lankan University undergraduates are spending more time to deal with internet activities such as social networking gaming and massaging. Thus from this study it is found that the moderating effect of gender for Facebook usage and the academic performance of government university undergraduates in Sri Lanka.

\section{Problem Statement}

People who live around the world are facing health -related matters because of using technological advancements in the wrong way. Mok et al. (2014) found that using smartphones regularly, keeps students away from physical activities, and academic work. Also, they reduce their sensory perception. When Undergraduates continuously faced with sensory overload (Misra \& Stikols, 2012), the memorizing power and the learning capacity will be reduced. World Health Organization (WHO 2018) also states that importance about digital wellness (using digital devices in the proper way) among the affected population by the use 
of an unhealthy way of digital technology, especially social media, university undergraduates have been highlighted. Several researchers found that because of the using in proper way of digital technology, negatively affected the university students' academic performance. Thus it is useful to research the moderating effect of gender on the relationship between Facebook usage and the academic performance of government university undergraduates in Sri Lanka.

\section{ili. Objective of the Study}

The main objective of this study is, to identify that gender moderates the relationship between Facebook usage and the academic performance of government university undergraduates in Sri Lanka.

\section{Research Method}

This study was conducted by secondary data. Primary data points Likert scale One state strongly disagree, and five indicate strongly disagree. The neutral. Respondents were the government university undergraduates, from the University University of Kelaniya, University of Sri Jayawardhanepura. One thousand and twenty (1020) questionnaires were distributed among the students, and one thousand, and ten questioners were returned. After removing incomplete deleting outliers 984 questionnaires were selected for the analysis. Multi group CFA analysis method used for the analysis.

\section{Conceptual Frame Work}

Conceptual moderate effect of gender to relationship between Facebook usage and the academic performance of the government university under graduates. Facebook usage is the independent variable and the academic performance is the dependent variable. Moreover the gender of the respondents took as the moderate variable of the study.

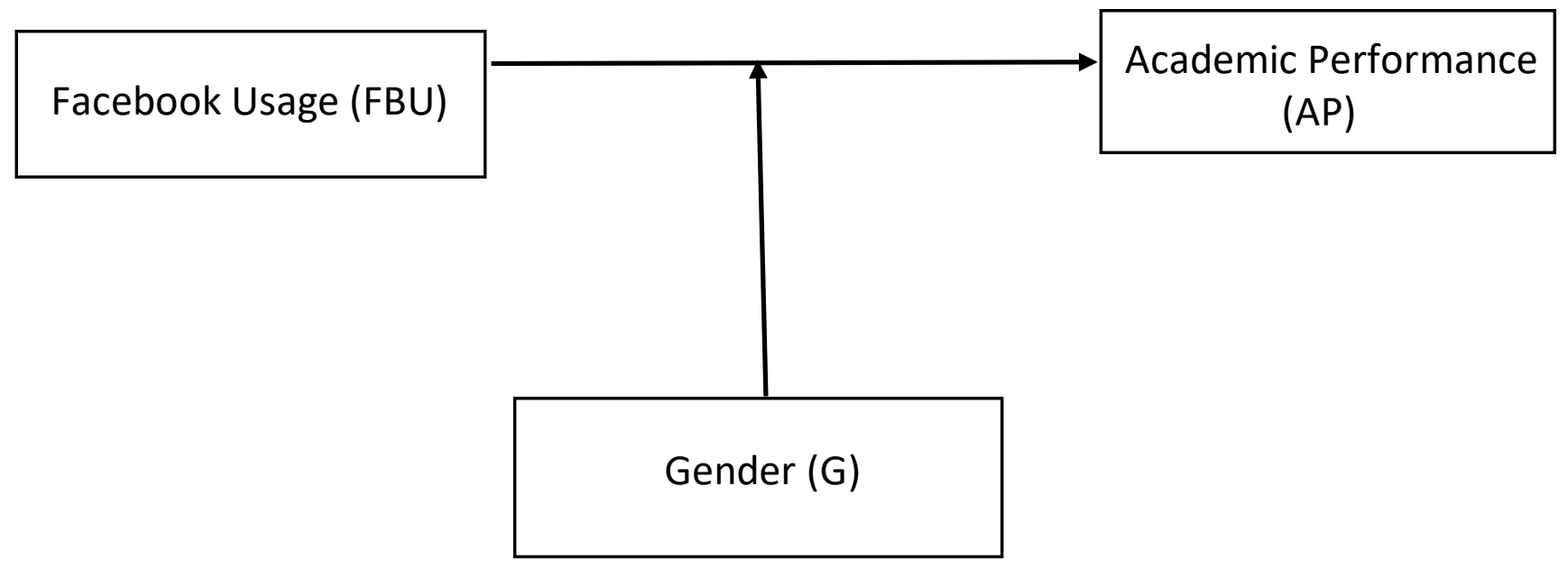

\section{Hypothesis of The Study}

Based on the conceptual framework main hypothesis was created to analyze the moderate impact as mentioned below.

H1: Gender moderates the relationship between Facebook usage and academic performance.

\section{Analysis}

To estimate the moderating effect of the moderate variable multi -group CFA analysis method is one of the common analysis method. (J.A.P. Kumari et al. 2019, Haque \& Awang 2019, Zainudin 2012) to identify the path interest in assessing the moderation impact, this analysis built the constrained model and the unconstrained model. The Constrained model called a parameter. The Unconstrained model remains the same. Both constrained and unconstrained models were run separately for estimate their chi-square. From the next step it was identified the deference of chi-square values between constrained and unconstrained models. If the difference between constrained and unconstrained models more than 3.84 with one degree of freedom, there is a moderation occurs in the selected path (J.A.P. Kumari ET. Al. 2019) Zainudin, 2012 to identify the moderating impact of the two paths, study has followed this method separately.

Table 1

\begin{tabular}{|c|c|c|c|c|c|c|c|c|c|}
\hline Path & Gender & $\begin{array}{c}\text { Constrained } \\
\text { Model }\end{array}$ & df & $\begin{array}{c}\text { Unconstrained } \\
\text { model }\left(\mathbf{X}^{2}\right)\end{array}$ & DF & $\Delta \mathrm{X}^{2}$ & $\Delta \mathrm{df}$ & $\begin{array}{c}\text { Results on } \\
\text { moderation }\end{array}$ & $\begin{array}{c}\text { Results on } \\
\text { hypothesis }\end{array}$ \\
\hline $\begin{array}{c}\text { FB to } \\
\text { ACP }\end{array}$ & Male & 1683.8 & 934 & 1329.1 & 933 & 354.7 & 1 & Significant & Supported \\
\hline
\end{tabular}


Table 1 shows the difference in Chi-square value of the constrained model and the unconstrained model. Chi-square value for the constrained model of the male was 1683.8 and unconstrained model indicates 1329.1. The Chi-square difference between the two models (Constrained model and unconstrained model) was 354.7, which is higher than 3.84. Thus the moderation result was significant. The second (2nd) table shows the difference between Chi-square value of model and the unconstrained model. Chi- square value for the constrained model of females was 1786.8, and the unconstrained model indicates 1405.7. The Chisquare difference between two Models (Constrained and unconstrained model) was 381.1, which is more than 3.84. Therefore the moderation result was significant. The Model fit summary table for male, the table represents the summary of the model fit. It indicates the model fit indices of constrained and unconstrained models for male on Facebook usage to Academic Performance. CFI (comparative fit index) TLI(Trucker-Luwis index), NFI (Normed fit index) were higher than 0.9. That indicates the RAMSEA (Root mean -square error of Approximation), (Holms-Smit 2000) for both constrained and unconstrained models were lower than 0.08. Threrefore the model was perfectly fit. The moderation test was significant for the relationship between Facebook usage and academic performance.

\begin{tabular}{|c|c|c|c|c|c|c|c|c|c|}
\hline Path & Gender & $\begin{array}{c}\text { Constrain } \\
\text { Model }\end{array}$ & df & $\begin{array}{c}\text { Uncons } \\
\text { model }\left(X^{2}\right)\end{array}$ & df & $\Delta \mathrm{X}^{2}$ & $\Delta$ df & $\begin{array}{c}\text { Results on } \\
\text { moderation }\end{array}$ & $\begin{array}{c}\text { Results on } \\
\text { hypothesis }\end{array}$ \\
\hline $\begin{array}{c}\text { FB to } \\
\text { ACP }\end{array}$ & Female & 1786.8 & 934 & 1405.7 & 933 & 381.1 & 1 & Significant & Supported \\
\hline
\end{tabular}

\begin{tabular}{|c|c|c|c|c|c|c|c|}
\hline Group & & CFI & TLI & IFI & NFI & RAMSCA & Comments \\
\hline \multirow{3}{*}{ Male } & & $>0.9$ & $>0.9$ & $>0.9$ & $>0.8$ & $>0.8$ & \\
\cline { 2 - 8 } & Constrained & .970 & .967 & .970 & .907 & .028 & Required \\
\cline { 2 - 7 } & Unconstrained & 1.000 & 1.000 & 1.000 & 1.000 & .054 & $\begin{array}{c}\text { Levels archives } \\
\text { in the field }\end{array}$ \\
\hline
\end{tabular}

\begin{tabular}{|c|c|c|c|c|c|c|c|}
\hline Group & & CFI & \multicolumn{1}{l|}{ TLI } & IFI & NFI & RAMSCA & Comments \\
\hline \multirow{3}{*}{ Male } & & $>0.9$ & $>0.9$ & $>0.9$ & $>0.8$ & $>0.8$ & \\
\cline { 2 - 8 } & Constrained & .956 &. .951 & .951 & .880 & .026 & Required \\
\cline { 2 - 8 } & Unconstrained & 1.000 & 1.000 & 1.000 & 1.000 & .045 & $\begin{array}{c}\text { Levels archives } \\
\text { in the field }\end{array}$ \\
\hline
\end{tabular}

\section{Vili. CONCLUSION}

In the modern world, people face health risks because of using digital devices in an incorrect way. In this situation university students are also highlighted, using of high range of digital devices. Especially mobile phones. Although several studies have proved that there is a negative impact on Facebook usage and the academic performance of university undergraduates, this study was investigated the moderating effect of gender on the relationship between Facebook usage and the academic. Performance of government universities undergraduates in Sri Lanka. To identify the moderating effect, use the multi -group analysis method. The test was significant for all paths. Chi-square deference between the constrained model and the unconstrained model was higher than 3.84 with 1 degree of freedom. Thus in conclusion. It has proved that gender moderates the relationship between Facebook usage and the academic performance of government university undergraduates in Sri Lanka.

\section{References Références Referencias}

1. Ali, S., Haider, S., Munir, F., Khan, H. \& Ahamed, A. (2013). Factors Contributing to the Students Academic Performance: A Case Study of Islamia
University Sub Campus. American Journal of Educational Research, 1(8), 283-289. DOI: 10.12691/education-1-8-3 Retrieved from: http:// pubs.sciepub.com/education/1/8/3/ Accessed on: 22.09.2017

2. Awang. Zainudin (2012). A Handbook on SEM. MPWS publisher, Malaysia.

3. Hoque, A.S.M.M., and Awang, Z. (2019). Does gender difference play moderating role in the relationship between entrepreneurial marketing and Bangladeshi SME performance? Accounting, 5(1), 35-52

4. Jinadasa, M. (2016). Representation of Youth Generation in the Mobile Phone and Internet Media in Sri Lanka. Psychology Research. 6 (5) Retrieved from: doi:10.17265/2159-5542/2016.05. 006 Accessed on 04.02.2018

5. Kumari J.A.P., Azam S.M.F., Kalidah S. (2019) The role of borrowers' Living Area and its Moderation effect on Relationship between Microfinance and Poverty Alleviation in Sri Lanka: Multi-Group CFA. Global Journal of Human -Social Science: E Economics. Volume 19 Issue 7 Version 1.0 year 2019.

6. Ramayah, T. and Lee, J.W.C. (2012). System characteristics, satisfaction and e-learning usage: a 
structural equation model (SEM).Turkish Online Journal of Educational Technology-TOJET, 11(2), 196-206.

7. Shao, A., Drewnowski, A., Willcox, D.C., Kramer, L., Lausted, C., Eggersdorfer, M., Mathers, J., Bell, J.D., Randolph, R.K., Witkamp, R. and Griffiths, J.C. (2016) Optimal nutrition and the ever-changing dietary landscape: a conference report. Retrieved from: https://www.ncbi.nlm.nih.gov/pmc/ articles/PMC5442251/ Accessed on: 05.01.2018

8. Darling, Nancy., Caldwell, L. Linda., \& Smith, Robert. (2005). Participation in School-Based Extracurricular Activities and Adolescent Adjustment. National Recreation and Park Association. 37 (1). Retrieved from: http://plaza.ufl.edu/asarkees/PSY\% 203220/ECsSelfEsteem/4-\%20Darling.pdf Accessed on: 22.10 .2017

9. Byrd, Jimmy. (2007). The Impact of Physical Activity and Obesity on Academic Achievement Among Elementary Students. Retrieved from: http://creative commons.org/licenses/by/2.0/Accessed on: 20.10. 2017

10. CDC. (2010). The Association Between SchoolBased Physical Activity, Including Physical Education, and Academic Performance. U.S. Department of Health and Human Services Centers for Disease Control and Prevention National Center for Chronic Disease Prevention and Health Promotion Division of Adolescent and School Health Retrieved from: https://www.cdc.gov/healthyyouth/ health_and_academics/pdf/pa-pe_paper.pdf 